\title{
Appraisal of a new scheme for prenatal screening for Down's syndrome
}

\author{
Trevor A Sheldon, John Simpson
}

\begin{abstract}
Objective-To appraise a new method of prenatal screening for Down's syndrome based on maternal serum concentrations of $\alpha$ fetoprotein, unconjugated oestriol, and human chorionic gonadotrophin combined with maternal age - the "triple test."

Design-Examination of the cost effectiveness of the triple test relative to screening only by maternal age over a range of population detection rates.

Setting-Leicestershire Health Authority.

Main outcome measures-Costs per affected fetus detected.

Results-The triple test is more cost effective than screening only by maternal age for risk cut off points for amniocentesis, resulting in a detection rate over $45 \%$. The most efficient detection rate is around $60-65 \%$, for which the cost per case detected is around $£ 29000$, though screening with higher detection rates is still likely to be cost beneficial.

Conclusions-Prenatal screening for Down's syndrome based on the triple test should replace screening based only on maternal age. Individual women's preferences should be elicited by the use of structured decision analysis in order to maximise utility and so increase the benefits of the screening programme.
\end{abstract}

\section{Introduction}

While current screening procedures for prenatal detection of neural tube defects have generally been regarded as successful, screening for Down's syndrome has been considered a failure. ${ }^{1}$ At present only women over 35 years of age are routinely offered amniocentesis because the higher incidence of Down's syndrome in babies born to these older mothers means that amniocentesis is cost beneficial and the number of women screened does not overstretch obstetric services.' With this policy the theoretical maximum proportion of fetuses with Down's syndrome that can be detected is around $30 \%$, as $70 \%$ of babies with Down's syndrome are born to mothers less than 35 years old, who are offered no form of routine screening. Screening based on maternal age in Britain results in a less than $20 \%$ reduction of the prevalence of births of babies with Down's syndrome. ${ }^{3}$

The prevalence of Down's syndrome has major resource implications as it is the third most important cause of mental handicap. In addition, more than $80 \%$ of the 1976-85 birth cohort survived to 5 years compared with only around $40 \%$ of the $1940-60$ cohort owing to improved treatment, particularly of cardiac defects, in the first few years of life. McGrother and Marshall estimated that current residential and community services for young mentally handicapped adults are facing a twofold increase in the number of clients with Down's syndrome. ${ }^{+}$The reporting by
Wald et al of a new and more effective screening procedure is therefore an important advance. ${ }^{5}$ By using a combination of maternal serum concentration of $\alpha$ fetoprotein, unconjugated oestriol, and human chorionic gonadotrophin plus maternal age the rate of false positive results of the screening procedure declined to $0.5 \%$ at a $30 \%$ detection rate compared with $5 \%$ for screening based only on maternal age. This new test can be used routinely to estimate the risk of having a baby with Down's syndrome in women of all ages in the second trimester. In this paper we report an economic appraisal of the "triple test," as a prenatal screening procedure offered to all pregnant women at around 16 weeks' gestation by using data from Leicestershire. ${ }^{6}$ The aim was to assess whether the test should replace screening based only on maternal age.

There have been several cost-benefit analyses that have shown prenatal screening for Down's syndrome based on maternal age to be cost beneficial at risk cut off points around one in 200 (for women over 35).278 More recently a screening policy based on maternal age and serum $\alpha$ fetoprotein concentration was thoroughly appraised and shown to be cost beneficial. ${ }^{9}$ In their paper Gill et al estimated the net present value of the excess cost to society of a child with Down's syndrome to be around $£ 90000$ (with a $7 \%$ discount rate). ${ }^{9}$ This amount is most probably an underestimate for two reasons. Firstly, the costs of social service and residential care, which are the largest costs, have risen faster than inflation. Secondly, the life expectancy of children with Down's syndrome is still increasing: McGrother and Marshall's 1981-5 cohort in Leicestershire had a $93 \%$ survival to one yeart compared with $87 \cdot 5 \%$ in the $1976-80$ cohort reported on by Gill et al. ${ }^{9}$

The valuations implicit in many cost-benefit analyses raise important ethical issues. ${ }^{10}$ Some would question whether we should seek to prevent the birth of "imperfect individuals." These ethical issues cannot be reduced to economic considerations, and in this paper, by examining cost effectiveness alone, we make no judgments on these issues.

\section{Method}

We compared the cost effectiveness of avoiding the birth of a baby with Down's syndrome by using the triple test with that by using screening based only on maternal age, which is the system currently in operation in Leicestershire. "The chosen measure of effectiveness was the cost per birth of a baby with Down's syndrome avoided, and this was calculated for different detection rates. Only the direct costs of testing, amniocentesis, termination, administration, and counselling were considered.

Table I gives the maternal age specific incidence of Down's syndrome in Leicestershire. Breaking this down on an annual basis, about 11742 babies are born annually, of whom $12 \cdot 3$ have Down's syndrome-an incidence of about 1.05 per 1000 live births. ${ }^{4}$
Correspondence to:

Mr Sheldon.

$B M 7$ 1991;302:1133-6 
TABLE I-Incidence of Down's syndrome in Leicestershire, 1980-5, according to maternal age $e^{+}$

\begin{tabular}{lccc}
\hline Age & $\begin{array}{c}\text { Incidence } \\
\text { (per 1000 live births) }\end{array}$ & No of cases & $\begin{array}{c}\text { No of } \\
\text { live births }\end{array}$ \\
\hline$<20$ & $0 \cdot 51$ & 3 & 5882 \\
$20-24$ & $0 \cdot 63$ & 14 & 22222 \\
$25-29$ & $0 \cdot 89$ & 22 & 24719 \\
$30-34$ & $0 \cdot 97$ & 13 & 13402 \\
$35-39$ & $4 \cdot 40$ & 16 & 3636 \\
$40-44$ & $9 \cdot 01$ & 5 & 555 \\
$\geqslant 45$ & $27 \cdot 77$ & 1 & 36
\end{tabular}

Table II gives an example of the specificity and sensitivity of the triple test and its practical effect based on the calculations of Wald et al. ${ }^{5}$ This assumes ideal conditions of a $100 \%$ uptake of the triple test and $100 \%$ acceptance of amniocentesis, based on women with a risk of having a fetus with Down's syndrome of at least one in 250 being offered amniocentesis. It should, however, be noted that most women in this category will have a higher individual risk, the average being one in $65 .^{3}$

TABLE II - Predicted performances of triple test ${ }^{\star}$ with women with at least a one in 250 risk of having a fetus with Down's syndrome being offered amniocentesis, assuming $100 \%$ uptake of test and amniocentesis

\begin{tabular}{|c|c|c|c|}
\hline $\begin{array}{l}\text { Triple test } \\
\text { result† }\end{array}$ & $\begin{array}{c}\text { True positive } \\
\text { result (on } \\
\text { amniocentesis) }\end{array}$ & $\begin{array}{l}\text { True negative } \\
\text { result (on } \\
\text { amniocentesis) }\end{array}$ & Total \\
\hline \multicolumn{4}{|l|}{ All ages: } \\
\hline Positive & $7 \cdot 7$ & $599 \cdot 4$ & $607 \cdot 1$ \\
\hline Negative & 4.9 & $11388 \cdot 0$ & $11392 \cdot 9$ \\
\hline Total & $12 \cdot 6$ & $11987 \cdot 4$ & $12000 \cdot 0$ \\
\hline \multicolumn{4}{|l|}{$<35$ years: } \\
\hline Positive & $5 \cdot 3$ & $551 \cdot 5$ & $556 \cdot 8$ \\
\hline Negative & $3 \cdot 4$ & $10477 \cdot 8$ & $104 \div ! \cdot 2$ \\
\hline Total & $8 \cdot 7$ & $11029 \cdot 3$ & $11038 \cdot 0$ \\
\hline \multicolumn{4}{|l|}{$\geqslant 35$ years: } \\
\hline Positive & $2 \cdot 2$ & $35 \cdot 1$ & $37 \cdot 3$ \\
\hline Negative & 1.5 & $666 \cdot 2$ & $667 \cdot 7$ \\
\hline Total & $3 \cdot 7$ & $701 \cdot 3$ & $705 \cdot 0$ \\
\hline
\end{tabular}

*Calculations based on those of Wald et al.

†Assumes a detection rate of $61 \%$ and a false positive result rate of $5 \%$.

Overall, we predicted that $7 \cdot 7$ out of $12.6(61 \%)$ fetuses with Down's syndrome would be detected, of which $5 \cdot 3$ would be in women under 35 who previously would not have been offered screening. Applying the test would result in 607 women being offered amniocentesis, $7 \cdot 7(1 \cdot 3 \%)$ of whom would have an affected fetus. Therefore, 599.4 women would have a false positive test result and so have amniocentesis unnecessarily. Thus, assuming a miscarriage rate associated with amniocentesis of $0.5 \%$, there would be around three spontaneous abortions of unaffected fetuses. Also, 4.9 women would be falsely reassured that they do not have an affected child. Of these, 1.5 would be older women who previously would have been offered amniocentesis in Leicestershire. Thus the replacement of screening based on maternal age with the triple test, with a risk of one in 250 as a cut off point for amniocentesis, would result in a net increase of 3.8 affected fetuses detected a year $(31 \%)$. In theory, double the detection rate can be achieved with a slight reduction in the number of women undergoing amniocentesis. This has been confirmed in practice. ${ }^{12}$

Many women aged over 35 offered amniocentesis under the present scheme refuse the investigation. Younger women, however, when informed of a high risk of having a child with Down's syndrome, would probably be more likely to accept amniocentesis, and termination if the result is positive, as many of the considerations affecting older mothers do not affect them. In addition, a higher percentage of older women
Sample calculation of cost per avoided birth of a baby with Down's syndrome by using triple test (based on figures in table II)

Cost per procedure

Measurement of oestriol and human chorionic gonadotrophin concentrations

Amniocentesis (including recall and counselling) $\$ 95$

Termination of pregnancy (including counselling)

Example 1

(Assuming 100\% take up of triple test and 100\% acceptance of amniocentesis)

12000 Tests of oestriol and chorionic gonadotrophin concentrations $£ 120000$ 607 Amniocentesis procedures

$7 \cdot 7$ terminations

Total $£ 184980$

Average cost per avoided birth $=184980 / 7 \cdot 7=£ 24023$

Example 2

(Assuming $80 \%$ take up of triple test and $75 \%$ acceptance of amniocentesis)

9600 Tests of oestriol and chorionic

gonadotrophin concentrations

$364 \cdot 2$ Amniocentesis procedures

$£ 96000$ $4 \cdot 6$ Terminations

$£ 34600$

Total $£ 134970$

Average cost per avoided birth $=134970 / 4 \cdot 6=£ 29341$

Assumptions:

Births per year $=12000$

Incidence of Down's syndrome $=1 \cdot 05 / 1000$ live births

Detection rate of $61 \%$ (risk cut off point of one in 250 for amniocentesis)

would probably consider themselves at risk if this is indicated in a positive blood test result.

The box gives a sample calculation of the average cost per avoided birth of a baby with Down's syndrome by using the triple test (based on. the assumptions in table II). The calculations are presented both using ideal $(100 \%)$ and the more realistic assumptions of a take up of the triple test of $80 \%$ (as is currently the case for measurement of $\alpha$ fetoprotein concentration) and an acceptance rate of $75 \%$ for amniocentesis. The costs were supplied by the clinical directors of the relevant departments at Leicester Royal Infirmary.

The cost calculations assume that there is sufficient capacity in the laboratories and clinical services to cope with the extra workload without a change in unit costs. In economic parlance we assumed a horizontal average cost curve. As $\alpha$ fetoprotein concentrations are already routinely measured in Leicestershire the costs of this test plus associated screening are not included in the cost effectiveness calculations.

We repeated these calculations for different risk cut off points, and hence detection rates. The lower the risk cut off point used, and hence the greater the number of women undergoing amniocentesis, the higher the detection rate. The average cost per fetus with Down's syndrome detected and termination of the pregnancy was compared with that derived from a screening programme based only on maternal age.

\section{Results}

Table III shows the average cost per avoided birth of a baby with Down's syndrome at different detection rates for the scheme based on maternal age and the triple test scheme. The cost effectiveness varies for different detection rates. The triple test has large fixed costs (assay of maternal serum) that are independent of the risk cut off point, so the average cost falls as the 
detection rate is increased and then rises only slowly. Conversely, the scheme based on maternal age gets more expensive per affected fetus as the detection rate increases.

These results indicate that the triple test is more cost effective than an equivalent programme based on maternal age at detection rates above $45 \%$ (below a risk cut off point of about one in 110). On this evidence programmes currently based only on maternal age should be replaced with screening by the triple test. In addition, even though we have not included all the costs associated with screening for and terminating affected pregnancies, which would be needed for a full cost-benefit analysis, ' it is clear from the figures that the triple test is likely to be cost beneficial at detection rates above $60 \%$.

It is important to assess the sensitivity of the results to variations in assumed uptake and acceptance rates. The cost per case is unaffected by changes in the rate of uptake of the triple test, though this will influence the absolute number of fetuses with Down's syndrome detected. On the other hand, increases in the acceptance rate for amniocentesis, and hence the numbers of affected fetuses detected, will reduce the cost per case. In screening based on maternal age the cost per case is unaffected by either of these variables.

To facilitate the application of these results to other health districts a sensitivity formula has been derived to enable a correct cost per case to be calculated given different conditions (appendix). To work out the change in the cost per case avoided from the figures given in table III appropriate values should be inserted into the formula: (cost per triple test) (1/acceptance rate $-1 \cdot 33) /($ prevalence) (detection rate).

The rates of detection and acceptance of amniocentesis are expressed as proportions and the prevalence as a number per 1000 births. For example, the change in the cost per baby born with Down's syndrome from that shown in table III for a $100 \%$ acceptance rate if the cost of the triple test was $£ 10$ and the prevalence 1.05 per 1000 for a detection rate of $61 \%$ is as follows:

$$
10 \times 1000 / 1 \cdot 05 \times 0.61\left(\frac{1}{1}-1 \cdot 33\right) \approx-£ 5000
$$

In other words the average cost goes down to about $29000-5000=£ 24000$ (to the nearest $£ 500$ ). This is close to the figure given in the box (example 1). The sensitivity of the average costs (to the acceptance rate) depends on the detection rate and therefore on the minimum risk cut off point used (figure).

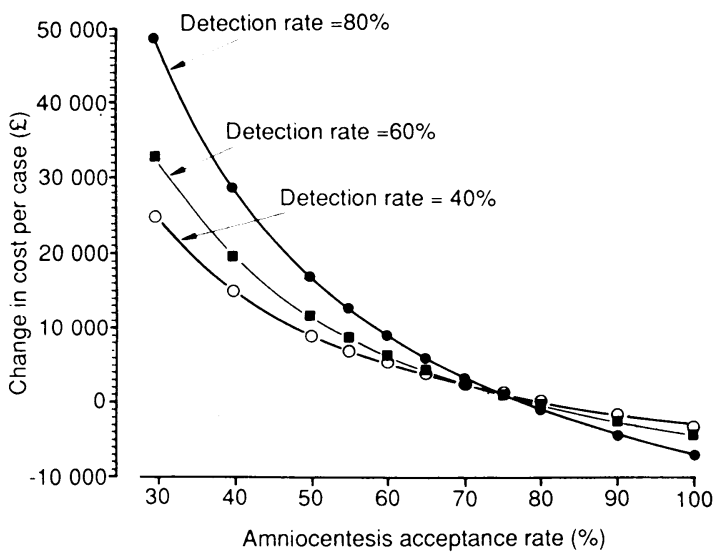

Sensitivity of cost per avoided birth of a baby with Down's syndrome to acceptance rate for amniocentesis at different detection rates

\section{Discussion}

The triple test has been shown to be more cost effective above certain reasonable detection rates than prenatal screening for Down's syndrome based only on maternal age. There are two main advantages of the triple test. Firstly, it can increase the detection of Down's syndrome with little change in the number of women undergoing amniocentesis, although there will be an absolute increase in the number of women undergoing amniocentesis at first (when the test is not already being offered to women over 35 with a relatively high take up). Secondly, it makes available a screening programme to pregnant women of all ages. Thus in addition to being more cost effective it is also more equitable in that all women in the same risk band will be offered amniocentesis irrespective of their age.

With the new test some older women who previously were offered amniocentesis by virtue of their age may be denied the facility. If the test was $100 \%$ sensitive this would not matter, but in two years of a programme using a minimum risk cut off point of one in 250 in Leicestershire about three fetuses with Down's syndrome in women over 35 will not be detected. However, it may not be cost beneficial to increase the detection rate to the extent that all of these fetuses are likely to be detected.

This problem reflects the fact that cost-benefit analysis looks at aggregate welfare by using measured costs and benefits, while ignoring many personal, intangible factors - for example, feelings of regret, relief, and anxiety - which are difficult to measure on a common monetary scale but which have a large bearing on individual welfare (G Mooney and M Lange, United Kingdom economists study group meeting, Dublin, Ireland, 1990). The optimum screening policy identified as the most cost beneficial, which informs planning decisions made on behalf of the public as a whole, may not be optimum for individual women. For example, it is commonly held that the benefits which accrue in prenatal diagnoses are confined to those cases in which an affected fetus is detected (with certainty) and aborted or a woman is correctly reassured that she does not have an affected fetus (a true negative result). ${ }^{13}$ However, there is evidence to indicate that women value (and are willing to pay for) information about the fetus that reduces uncertainty, even if they do not wish to avoid the birth of a handicapped baby (G Mooney and M Lange, 1990). ${ }^{14}$ Therefore, a woman's access to a screening test should be independent of any decision she may make about the continuation of her pregnancy. ${ }^{15}$ In the past doctors have made decisions on termination based on their own implicit preferences rather than the woman's. ${ }^{16}$ If the objective of a health care service is to maximise welfare these factors need to be taken account of in the decision making process. Given that they may vary greatly among women and over time, this can be done only on an individual basis. One method of taking into account the preferences of individual women is by decision analysis, which has been applied to various clinical problems as an aid to decision making. ${ }^{1720}$ Though decision analysis has been used widely in the United States and Canada, it is only slowly gaining general acceptance in the British clinical context in general and obstetrics in particular. ${ }^{21}$ This technique has been used successfully as part of a screening programme based on maternal age (the Harvard Community Health Plan) in the United States. ${ }^{223}$ As methods of prenatal screening for congenital abnormalities become more efficient the costs of providing a decision analysis service will become more feasible as it will probably increase the utility (satisfaction or welfare) of individual women while still representing a large benefit to society as a whole.

We thank the following staff at the Leicester Royal Infirmary: $\mathrm{Mr} \mathrm{N}$ G Naftalin, clinical head of service, obstetrics and gynaecology unit; Dr J Falconer-Smith, consultant in chemical pathology; and Dr I Young, senior lecturer in clinical genetics. We also thank Ms S Haggerty for secretarial help. 
Appendix: derivation of sensitivity formula

$\mathrm{N}=$ number of women having triple test; $\mathrm{p}=$ prevalence of Down's syndrome; $p^{\star} N=$ total number of fetuses with Down's syndrome; $\mathrm{DR}=$ detection rate; $\mathrm{FPR}=$ false positive rate; $p^{\star} N^{\star} D R^{\star} A R=$ number of women with true positive results who have amniocentesis; $(1-p)^{\star} N^{\star} F P R \star A R=$ number of women with false positive results who have amniocentesis; $\mathrm{p}^{\star} \mathrm{N}^{\star} \mathrm{DR} \mathrm{R}^{\star} \mathrm{AR}=$ number having an abortion (all positive amniocentesis results); $T \mathrm{~T}=\mathrm{cost}$ of triple test per person $\mathrm{Am}=\mathrm{cost}$ of amniocentesis; $\mathrm{Ab}=$ cost of abortion $\mathrm{AR}=$ amniocentesis acceptance rate.

The total cost of avoiding the birth of all detected fetuses with Down's syndrome has three components: the cost of the triple test $\left(T^{\star}{ }^{\star} \mathrm{N}\right)$; the cost of amniocentesis in all women with true positive results or false positive results; and the cost of abortion.

Total cost $=T^{\star} T^{\star} N+A m^{\star}\left[p^{\star} N^{\star} D R+(1-p)^{\star} N^{\star} F P R\right]^{\star} A R$ $+A b^{\star} p^{\star} N^{\star} D R \star A R$

Average cost $=$ Total cost $/$ Number of births avoided $\left.=T T^{\star} N+A m^{\star}\left[p^{\star} N^{\star} D R+(1-p)^{\star} N^{\star} F P R\right)\right]^{\star} A R$ $\frac{+A b^{\star} p^{\star} N^{\star} D^{\star} A R}{p^{\star} N^{\star} D R^{\star} A R}$

The only term that varies as the acceptance rate (AR) changes is the one on the left. Assuming an acceptance rate of $75 \%$ as in table III this term is:

$$
\frac{T T(1 / A R)}{p^{\star} D R}=\frac{T T(1 / 0.75)}{p^{\star} D R}=\frac{T T(1.33)}{p^{\star} D R}
$$

Thus changes in acceptance rate affect the average cost according to the formula given in the text:

Change in average cost $=$ (cost per triple test $)(1 / \mathrm{AR}-1 \cdot 33) /$ (prevalence rate) (detection rate).

1 Ferguson-Smith M. Neural tube defects and Down's syndrome: a success and a failure. In: Screening for fetal and genetic abnormality. London: King's Fund Centre, 1987

2 Hagard S, Carter FA. Preventing the birth of infants with Down's syndrome: a cost benefit analysis. BMF 1976;i:753-6.
3 Wald NS, Cuckle HS. Recent advances in screening for Down's syndrome and neural tube defects. In: Rodeck C ed. Balliere's clinical obstetrics and gynaecology. Vol 1. No 3. London: Bailliere Tindall, 1987: 649-76.

4 McGrother CW, Marshall BS. Recent trends in incidence, mortality and survival in Down's sundrome. F. Ment Defic Res 1990;34:49-57.

5 Wald NJ, Cuckle HS, Densem JW, $t$ t al. Maternal serum screening for Down's syndrome in early pregnancy. BMF 1988;297:883-7.

6 Mckeown T. Validation of screening procedures. In: Screening in medical care: reviewing the evidence, a collection of essays. London: Oxford University Press, 1968

7 Henderson JB. Economic evaluation of screening for fetal and genetic abnormality. In: Sireening for fetal and genetic abnormality. London: King's Fund Centre, 1987

8 Sadovnic AI), Baird PA. A cost-benefit analysis of prenatal detection of Down's syndrome and neural tube defects in older mothers. Am f Med Genet 1981:10:367-78.

9 Gill M, Murday V, Slack J. An economic appraisal of screening for Down's syndrome in pregnancy using maternal age and serum alpha fetoprotein concentration. Soc Sci Med 1987;24:725-31.

10 Callan J. The economics of pre-natal screening. York: Centre for Health Economics, University of York, 1988. (Discussion paper No 42.)

11 Drummond MF, Stoddart GL, Torrance GW. Methods for the economic evaluation of health care programs. Oxford: Oxford University Press, 1987.

12 Cartmill RS, Thornton JG, Williams J, Holding S, Lilford RJ. Clinical experience with the triple test for Down's syndrome screening. Fournal of Perinatal Medicine 1991 (in press

13 Dowie J. Professional judgement, introductory text 5. D321. Milton Keynes: Open University, 1987:9.

14 Richards M. Some reflections on fetal diagnosis. In: Screening for fetal and genetic abnormality. London: King's Fund Centre, 1987.

15 King's Fund Forum Consensus Statement. Screening for fetal and genetic abnormality. London: King Edward's Hospital Fund for London, 1987.

16 Drummond M. Personal view. BM7 1988:296:566.

17 W'einstein MC, Fineberg HV, Elstein AS, et al. Clinical decision analysis. Philadelphia: W B Saunders, 1980.

18 Kassiner JP, Moskowitz AJ, Lau J, Park SG. Decision analysis: a progress report. Ann Intern Med 1987;106:275-91.

19 Doubilet P, McNeil BJ. Clinical decision making. Med Care 1985;23:648-62. 20 Schwartz W'B. Decision analysis: a look at the chief complaints. $N$ Engl 9 Med 1979;300:556-9.

21 Thornton JG. Decision analysis in prenatal diagnosis: measuring patients' values. In: Lilford RJ, ed. Prenatal diagnosis and prognosis. London values. In. L.lford

22 Pauker SP, Pauker SG. Prenatal diagnosis: a directive approach to genetic counselling using decision analysis. Y'ale o Biol Med 1977; 50:275-87.

23 Pauker SP, Pauker SG. The amniocentesis decision: ten vears of decision analytic experience. March of Dimes Birth Defects Foundation, birth defects: original article series, 1987;23:151-69.

(Accepted 21 February 1991)
Department of Community

Medicine, University of

Edinburgh, Medical

School, Edinburgh EH8

9AG

F G R Fowkes, FRCPED,

reader

P M Fulton, FRCPED, senior

lecturer

Correspondence to: $\mathrm{Dr}$

Fowkes

BMF 1991;302:1136-40

\section{Critical appraisal of published research: introductory guidelines}

\author{
F G R Fowkes, P M Fulton
}

Reading medical journals can be time consuming, and most doctors have become adept at skimming contents by reading titles and perusing abstracts. Getting to grips with the details of papers and conducting a critical appraisal of the research may be a task many find difficult because they are not research experts and have not had training in the appraisal of papers during medical education. This difficulty may be particularly acute for junior doctors embarking on their first research towards a higher degree.

The purpose of appraising a paper is to discover if the methods and results of the research are sufficiently valid to produce useful information. The prime objective is not necessarily to assess the authors; sometimes a research project may be the best which could be carried out but, because of the unforseen difficulties, the results are of limited value. Neither is the purpose to decide if the research is well presented, beautifully written, and finely illustrated. A critical appraisal is concerned with assessing the hard facts of the research.

In this article we set out simple guidelines for appraising medical research on patients or in the general population. These guidelines do not cover all categories of study design, and individual guidelines are not necessarily relevant to every study. Instead they are reminders of the important features which should be considered when appraising a paper. The statistical content of papers has been discussed ${ }^{2}$ and, although important, is not reviewed here.

\section{Starting the appraisal}

\section{REVIEW A STRUCTURED ABSTRACT}

An abstract should summarise the research succinctly and include the objectives, study design, important results, and the authors' conclusions. When starting to appraise an article reviewing a structured abstract is particularly helpful because the different components of the research can readily be identified. ${ }^{34}$ Serious flaws may be detected at this stage.

\section{WHAT ARE THE OBJECTIVES OF THE RESEARCH?}

The next step is to identify the precise objectives of the research. These should be stated in the introduction to the paper or may be given in the abstract. A principal goal of appraisal is to establish whether research objectives have been met, and the most precise form of the objectives should be sought. For example, the specific objective "To determine the effect of one week's bed rest, compared with normal activity, on the severity and duration of acute lumbosacral pain" is more useful than the general objective "To examine the role of bed rest in the management of back pain." Unfortunately, specific objectives are often not stated in papers and we may even have to peruse the results in order to find the apparent objectives. Asking ourselves "What are the authors really trying to measure?" can help with this.

\section{WHAT IS THE OVERALL STUDY DESIGN?}

Before dissecting the methods in detail the overall design of the study should be clarified, as this helps to 